\title{
Towards a Method for Mobile Learning Design
}

\author{
Genevieve Stanton and Jacques Ophoff \\ Department of Information Systems, University of Cape Town, \\ Cape Town, South Africa
}

\author{
stngen003@myuct.ac.za jacques.ophoff@uct.ac.za
}

\begin{abstract}
Mobile learning provides unique learning experiences for learners in both formal and informal environments, supporting various pedagogies with the unique characteristics that are afforded by mobile technology. Mobile learning, as a growing topic of interest, brings challenges of design for teachers and course designers alike. Current research on mobile learning has covered various aspects such as personalization, context sensitivity, ubiquity and pedagogy. Existing theories and findings are valuable to the understanding of mobile learning, however they are fragmented and separate, and need to be understood within the broader mobile learning paradigm. This paper unifies existing theories into a method for mobile learning design that can be generalized across mobile learning applications. This method develops from a strategy - seeking objectives, identifying the approaches to learning and the context in which the course will exist, to guide the content, delivery and structure of the course towards a successful implementation that is evaluated against the initial objectives set out.
\end{abstract}

Keywords: mobile learning, as-lived experience, mobile learning design

\section{Introduction}

Mobile learning has been an emerging topic since the introduction of cellular phones and wireless technology; recently this interest has picked up pace due to further technological advances that are making mobile technology simpler and more interesting to use as a means of learning (Burdick \& Willis, 2011; Weilenmann \& Juhlin, 2011). Mobile learning is the combination of mobile technology and its affordances that create a unique learning environment and opportunities that can span across time and place.

Learning is a form of communication, of transferring knowledge and information, so it makes sense that the most "ubiquitous form of communication" (Franklin, 2011) is used as a tool for learning. What is raised, however, is not so much whether mobile technology should be used but how it should be used. Various models for understanding mobile learning systems have been created and adapted to measure performance, user acceptance, understand the user's context, and understand and develop mobile systems

Material published as part of this publication, either on-line or in print, is copyrighted by the Informing Science Institute. Permission to make digital or paper copy of part or all of these works for personal or classroom use is granted without fee provided that the copies are not made or distributed for profit or commercial advantage AND that copies 1) bear this notice in full and 2) give the full citation on the first page. It is permissible to abstract these works so long as credit is given. To copy in all other cases or to republish or to post on a server or to redistribute to lists requires specific permission and payment of a fee. Contact Publisher@InformingScience.org to request redistribution permission. and technology (Parsons \& Ryu, 2006; Sha, Looi, Chen, Seow, \& Wong, 2012; Williams, 2009). The uniqueness of mobile learning lies in it being a ubiquitous, social, context sensitive, and collaborative tool (Ozdamli \& Cavus, 2011; Patokorpi, 2006).

Mobile learning design is the design of a mobile learning course taking into account what needs to be delivered, how it 
will be done and the structure of such a delivery. This design needs to look at the "real needs of instructors and learners" (Alvarez, Alarcon, \& Nussbaum, 2011) and at the social aspects that mobile technology was originally intended for to get the most out of mobile learning. In addition it should consider the 'as-lived-experience' of mobile learners (Kjeldskov \& Stage, 2012), because in essence learning is deeply social (Burdick \& Willis, 2011). However, the determining factor for mobile technologies in learning will be dependent on its adoption by both educators and the learners (Alvarez et al., 2011).

Williams (2009) considers the major element of a successful mobile learning platform to be the "instructional design"; by simply posting lecture content as-is on the Web, the teacher is not necessarily creating "a viable tool" for learners. While many universities have provided apps, these have been non-instructional, and thus there is little experience of how to deliver learning through mobile technology (Cheon, Lee, Crooks, \& Song, 2012).

Another issue is that "few researchers have discussed ways of integrating mobile devices with web-based learning systems to cover most learning processes by generating a ubiquitous learning environment" (Chen et al., 2008, p.78). Designers and teachers need to have a basic understanding of the various characteristics of mobile learning and how they can best be used. The use of traditional user experience knowledge is insufficient for this as it doesn't take into account those unique characteristics of mobile learning such as mobility and how smaller screens limit the type of content delivered (Chittaro, 2011; Costabile et al., 2008; Naismith, Lonsdale, Vavoula, \& Sharples, 2004).

Where mobile learning is a supporting tool to the classroom, understanding the contexts and teaching concepts are required to effectively implement the system (Alvarez et al., 2011). The theme that arises in the literature is one of understanding: the designer needs to be able to understand and conceptualize all aspects of the mobile learning system to be as effective as possible in delivering the objectives.

This paper looks at bringing together the research around mobile learning to create a method for mobile learning design that does not prescribe the content and structure but rather facilitates the process of planning and creating a course while ensuring that the various aspects such as technology, context, usability, and pedagogy are considered along with the objectives of the course.

This paper begins by defining what mobile learning is. From there it delves into the various characteristics of mobile learning and its affordances to learning as well as the many contexts of mobile learning and the consideration of an as-lived experience in mobile learning design. Next some existing processes for mobile learning design are discussed, as well as the main objectives of learning in general. Thereafter the paper examines the knowledge dimensions of learning and the categories of learning that can be translated into mobile learning. From these explorations this paper then presents and discusses a method for mobile learning design based on these areas, before being brought to a conclusion.

\section{Mobile Learning}

There are various definitions of mobile learning. The basic understanding is that mobile learning is the "provision of education and training on mobile devices" (Yousuf, 2007, p.117) or it is a combination of e-learning and mobile technology (Ketterl, Heinrich, Mertens, \& Morisse, 2007; Parsons \& Ryu, 2006). While mobile learning may resemble e-learning in some cases this view is limited in that it removes all other features of the mobile device such as messaging and it also excludes the limitations of mobile devices such as the small interface that limits the ability to simply view e-learning on a mobile device. 
A further look into what it is that makes mobile learning different to face to face and e-Learning is mobility. Being able to move around is a key feature that differentiates mobile learning from other learning environments; it is seen as freeing the learner from the classroom, allowing learning to take place anywhere and anytime. Mobility has become a major focus of mobile learning design alongside personalisation (Botha, Herselman, \& van Greunen, 2010; Costabile et al., 2008).

Developing the definition of mobile learning, Yordanova (2007) sees mobile learning as "learning that is wireless and ubiquitous" in nature. This ubiquity is a common concept brought up around mobile learning that is seen as not simply a portable device but "the ability to learn across contexts" (Al-masri \& Mahmoud, 2012, p.604; Cavus \& Al-Momani, 2011, p.1476). From these ideas, the understanding underlying this paper will be that mobile learning is unique by nature and is the combination of mobile technology and its affordances that create a unique learning environment and opportunities that can span across time and place.

Research on mobile learning has emphasized and repeated the advantage of using mobile technology because of the characteristics and opportunities that mobile learning offers. Common characteristics that are brought up in many research papers around m-learning are those of ubiquity, nomadicy, personalization, interactivity, and collaboration. The technology itself allows for these characteristics because of its size, weight and portability. The small screen size has been noted as a drawback. Being a part of most people's daily lives, mobile technology doesn't need to be taught and so learning can be integrated quickly and easily into a persons' everyday life (AlHmouz, Shen, Yan, \& Al-Hmouz, 2010; Cavus \& Uzunboylu, 2009; Ozdamli \& Cavus, 2011; Rogers, Connelly, Hazlewood, \& Tedesco, 2009).

\section{Mobile Learning Characteristics}

The mobile learning characteristics discussed here give a picture of what is contained in mobile learning and how it can be used most effectively to bring about learning. First the paper looks at the portability of mobile phones, which is categorized within nomadicy. Being nomadic in nature leads into the ubiquitous nature of mobile technology, the idea of instant connectivity and the ability to connect in any situation. With the idea of being nomadic and ubiquitous it is then important to consider the context sensitivity of mobile learning. Within these contexts the next characteristic to consider is the interaction and collaboration that mobile learning can afford. Finally, mobile learning also considers personalisation or the individuality of the user, their preferences etc. Figure 1 illustrates the major characteristics and contexts of mobile learning that are discussed here. 


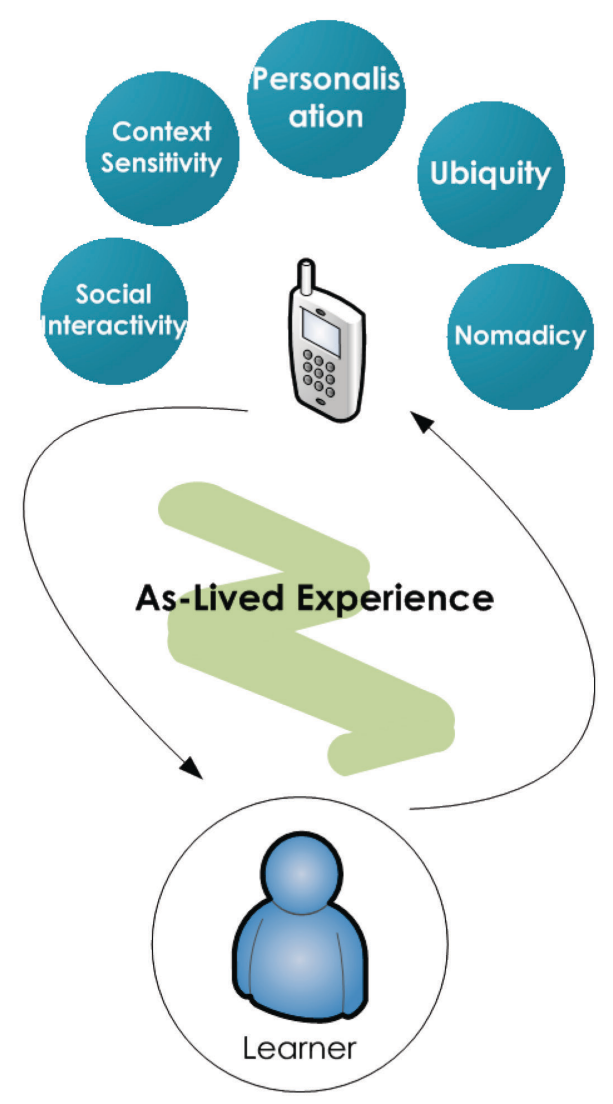

Figure 1: Contexts and characteristics of mobile learning paradigm

\section{Nomadicy}

The most obvious difference with mobile learning is its portability. Mobile devices can travel anywhere with a person with relative ease, but it's not just the moving around but rather a nomadicy. Nomadic refers to "a phenomenon in which the state of being on the move is the normal state and not a break from the normal"(Patokorpi, 2006, p.21); even when the device is disconnected, the learner is able to access certain material nomadically. So "being mobile is understood as a form of being-in-the-world" (Fällman, 2003 as cited by Fischer, 2011, p.19) This changes our perspective of mobile use from something that we are introducing to a learning environment to something that already exists and is part of that environment, as well as learning being something that is not exclusive to a formal situation but can be nomadic as well.

Being nomadic in nature is the very first intention of mobile technology and allows users of this technology to move about and still have the ability to use all the features of the device to make calls, search the web and more, the nomadic nature brings out technological possibilities coupled with the personal aspect of mobile phones (Arnold, 2003; Naismith et al., 2004). The learner is thus able to take their learning anywhere and anytime without the constraints of a classroom, making learning available at times that are more suitable to the learner, even on the move; this freedom empowers learners (Cavus \& Al-Momani, 2011).

The drawback of this nomadicy is that it expands the users context and control over the situation of learning, allowing for distractions and interruptions to be part of the learning experience (Costabile et al., 2008). Fischer (2011) focuses on the interruptions that users experience with mobile phones and has created a model to help understand the nature of both positive (such as reminders and initiating engagement) and negative interruptions (that affect the user's ability to 
continue a task). Fischer's (2011) main conclusion around interruptions was that, the degree to which something interrupts a user is dependent on the context; the importance they place on what is interrupting the situation; and the timing of it in each moment.

Interruptions can include messages, calls and reminders that can interrupt the flow of the context, either on the device while the user is learning or in the actual situation that the person is present in. The nomadic nature of the user implies that "the user is distracted and has a short attention span"(Botha et al., 2010, p.35). This short attention span is affected by the overwhelming amount of information available to an individual using their mobile phone, so it's important that mobile learning as a nomadic way of learning supplies users with exactly what they need in the right context (Bray, Epstein, Hill, \& Thomas, 2006). This leads us first to consider ubiquity in mobile learning.

\section{Ubiquity}

Ubiquity refers to the interconnectedness of the mobile device with its environment, and other devices, it's more than just being able to move about, it's being able to access information simply and fluidly in any situation (Patokorpi, 2006). "Mobile technologies forge ubiquitous learning spaces and experiences across different scenarios or contexts" (Sha et al., 2012). Ubiquity also refers to the spontaneity of mobile learning, which is allowed because of its on-the-move context. Ozdamli \& Cavus (2011) consider spontaneity as a defining characteristic, "revolutionising education" to being nomadic and contextualized. The ability to learn in just about any context with any mobile device is ubiquitous.(Chen et al., 2008)

"Mobile devices have become one of the most powerful technologies available to the individual for acquiring knowledge in a ubiquitous manner"(Al-masri \& Mahmoud, 2012, p.603). Being connected to the internet, through wireless networks, and telecommunications, means that the world is more connected than ever before. This influences the way we see ourselves in the world, where we are and who we're able to connect to, and the information that is available to us all the time; which leads us to consider what contexts exist in a mobile learning environment.

\section{Personalisation}

Mobile phones cannot know what context you are in and the sensitivities of it, such as if you are in a meeting or socializing. They act independently of the situational context (Fischer, 2011). It is however important that the context is considered in the design to give the user the best experience possible. A lot of research has been conducted in this area aiming to get to an intelligent device that can react to the environment and respond appropriately (Al-Hmouz et al., 2010; Kearney, Schuck, Burden, \& Aubusson, 2012).

Using a mobile device for learning personalizes learning and creates anonymity and privacy simply through ownership of that device and the control of the user. Numerous studies have been done to attempt to customize a mobile learning environment to a particular learner's context and history. One side of personalisation is allowing for the learner to "have the option to choose learning content based on their interest" (Al-Hmouz et al., 2010); they can also make small customizations to the look and feel of the content. Personalisation goes even further though, where algorithms have been produced that will use the data collected from the users performance to customize content that is at their level and preference of learning (Al-Hmouz et al., 2010; Ozdamli \& Cavus, 2011). This research is at a technological level and lacks the "user's point of view" (Patokorpi, 2006) towards being personalized.

Robert Kass (1991 as cited by Al-Hmouz et al., 2010, p.784) speaks about "systems that tailor their behavior to individual users' needs" as well as containing personal information about the user that can help to tailor the mobile technology's behavior. "Learning is no longer restricted by 
space and time"(Arnold, 2003; Sha et al., 2012) so it becomes fundamentally important that the user is able to call up the information that is required in their situational context. The learner should be able to choose when and where and how much learning to consume using their mobile devices (Williams, 2009).

\section{Social Interactivity}

Collaboration is highly supported for mobile learning. The technology removes borders and allows learners to collaborate with peers or teachers around the world, how and when they want to. This collaboration increases active participation by students. There is a parody at play here where mobile learning affords both privacy and freedom to the learner (Alvarez et al., 2011; Ozdamli \& Cavus, 2011; Patokorpi, 2006) and "it provides its users with a high degree of independence, mobility and flexibility"(Arnold, 2003 p.243) as well as allowing for teachers to respond "in ways that are meaningful to [the learner]" (Schultz, 2011).

Although there are many advantages to having this collaborative communication it can also be disadvantageous for the learner. Being out in the real world means there are plenty of distractions, that can disturb a learner's pattern of thought (Rogers et al., 2009), so when a learner is interacting with the learning environment it is just as easy for the learner to get involved in something that is happening more immediately in their situational context, and disconnecting from that engagement. The recent developments in mobile technology have created a higher level of interaction (Al-masri \& Mahmoud, 2012).

Mobile learning offers the opportunity to move beyond the formal classroom and allow more freedom for learning anywhere, anytime. The nature of mobile devices being portable and personal support many types of interaction (Naismith et al., 2004) "One way of ensuring that learners engage in fruitful collaboration is to engage them in structured interactions, based on prescribed rules establishing how they should form groups, collaborate, and solve problems" (Alvarez et al., 2011, p.1962)

A useful model for understanding the types of interactions that exist has been proposed by Moore (1989 as cited by Abdous \& Yen, 2010), in this model there are three types of interaction: learner-to-content interaction (LCI), learner-to-teacher interaction (LII), learner-to-learner interaction. Willis and Gunawardena (1994 as cited by Abdous \& Yen, 2010) introduced the fourth type of interaction: learner-interface interaction.

These interactions are highly supported by mobile technology and can be utilized quite effectively in a mobile learning environment. Learner-to-Content interaction plays a key role in forming ways of thinking for the learner that will facilitate learning. Learner-to-Teacher interaction is a motivational and facilitation role in learning as well as providing a supporting role. Learner-toLearner interaction allows for more collaborative to take place. Learner-to-interface interaction is about the learner's experience with the mobile learning and the quality of it (Abdous \& Yen, 2010). These interactions also create formal, informal, social and personal spaces for learning.

\section{Limitations of Mobile Learning}

There are many limitations that need to be considered with mobile learning. The obvious limitations are the ones of the small screen size, the audio quality and connection to the network affecting the speed and quality of delivery for learning content. While a small interface might be limiting in regard to what can be delivered to a learner it could also be advantageous, in that it forces the content to be to the point and meaningful or presented in a more creative manner, which could benefit learners. Attention span or the ability to take in large amounts of information at a time is a shortcoming of learning itself, so the limitation of the small interface actually assists this short- 
coming by catering for it in small chunks of information (Chittaro, 2011; Fischer, 2011; Yordanova, 2007).

In some cases the limitation of battery life and the small screen life mean that mobile learning might be better used as a support system to the traditional learning, as a middle path between elearning and the classroom; allowing for just what is necessary when on the move (Chen et al., 2008).

Moving away from the technical aspects of the devices, the vast amount of information available on the internet has made it a common resource to find out or learn about something. Mistaking the internet as "reflecting reality" (Bray et al., 2006) can be a problem for learners as misunderstandings or confusion arises over a topic. It is necessary that mobile learning guides the student, and helps to filter unnecessary information.

Common design issues in mobile learning are those of: "usability, communication and interactivity" (Ali, Ouda, \& Capretz, 2012). Other things that should be considered are features such as location-based services that could be seen as an infringement on a learner's privacy, so a learner may not be willing to allow for it. If learning becomes so invasive in an informal environment that it overtakes their social network then learners may have more reason to be rid of the mobile learning than to use it (Naismith et al., 2004).

After exploring the many characteristics of mobile technology and the affordances to mobile learning as well as its limitations, the next section focuses on the contexts that surround mobile learning.

\section{Context Sensitivity in Mobile Learning}

Keeping in mind that mobile learning is ubiquitous and nomadic in nature, this section considers the contexts that exist, are crossed and are created through mobile learning. Context is important as it can help in the design of the mobile learning environment. Delivering learning content that is based on the current context of a user should be an important goal of mobile learning(AlHmouz et al., 2010).

"Today, we live in two spheres of existence, a physical sphere and a digital sphere" (Bray et al., 2006) and then these spheres overlap and this can be seen as the interacting of these two worlds. These two spheres are often out of our control, but what can be controlled is what and how we deliver learning into these two spheres to influence the user's interaction within these overlapping spheres. Further investigation into these spheres is required. Mobile devices and technology in general are now part of our daily lives, and this means that there exists very little separation between work, socializing and our private lives as it is all accessible wherever we are (Weilenmann \& Juhlin, 2011).

Within these digital and physical sphere's Al-Hmouz et al. (2010) proposes a framework for learner personalisation that takes into account different contexts, he refers to these as statuses. The four major statuses that Al-Hmouz et al. (2010) propose are (1) "situation status", "learner status", "knowledge and shared properties status" and "educational activity status." The FRAME model as designed by Koole (2009) identifies information contexts and describes how these overlap each other to create further contexts; the main contexts are the device aspect, learner aspect and social aspect. Combining these perspectives this paper has grouped the contexts into three major contexts that will be explored more fully. These are the (1) learner's status, referring to the person's personal being and preferences, the (2) situational context refers to the world that exists physically and nomadically around the user and then the (3) learning environment context that takes into account the environment that is created through the integration of the digital and physical spheres. These contexts are represented in Figure 2 for visual understanding. 


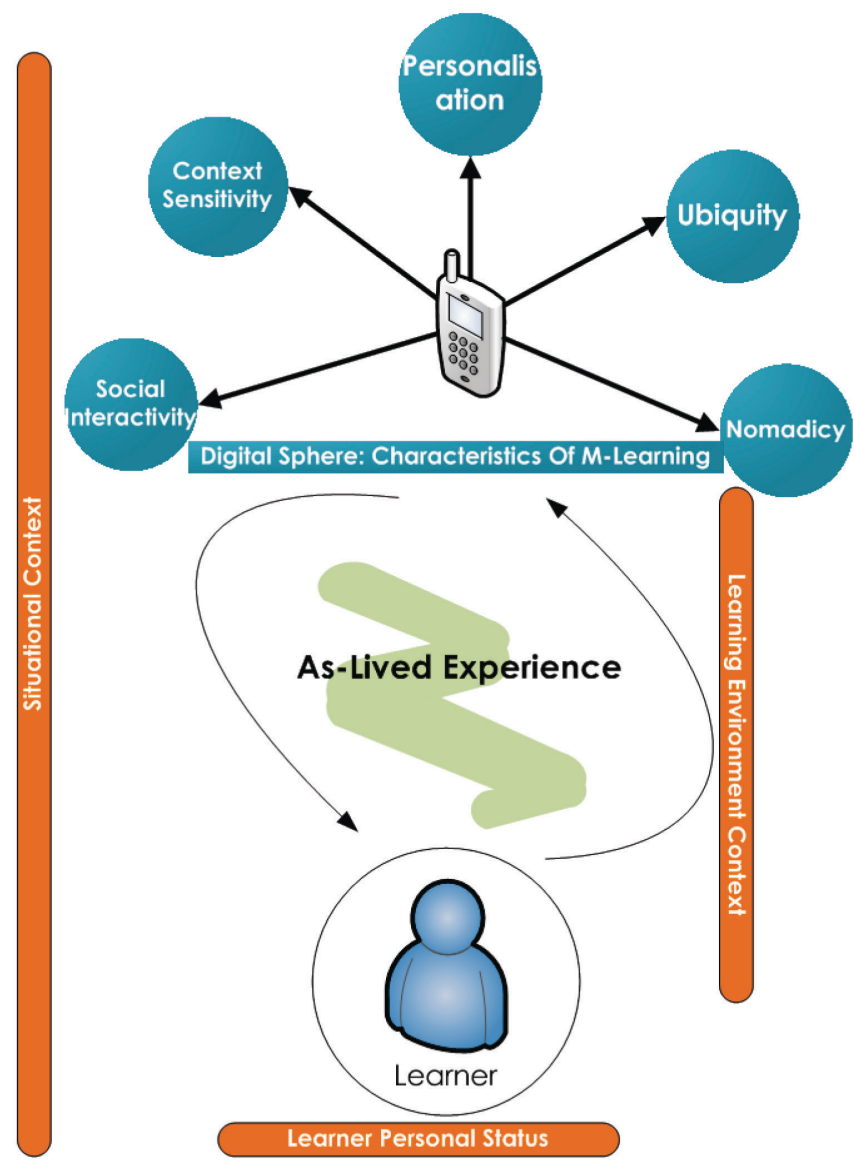

Figure 2: Different contexts in mobile learning

\section{Learner's Personal Status}

The learner's context considers aspect of the learner such as preferences, demographic information, and learner history as well as "cognitive ability, memory, prior knowledge, emotions and possible motivations" (Al-Hmouz et al., 2010; Koole, 2009).

Being in a constantly changing environment means there are numerous influences surrounding the learner that can affect their behavior, emotional state and concentration and ultimately their ability to use the mobile learning service appropriately. While there is no control over these aspects it is important to keep these in mind when considering the implications of our design.

\section{Situational Context}

Context can be many things for mobile learning. For one, being mobile in nature means that every situation brings its own context that is unpredictable and determined by the user and their environment; thus "mobility and context are seen as inextricably intertwined" (Fischer, 2011, p.19). The nomadic and ubiquitous nature of mobile technology means that a user's context is constantly changing due to that movement (Patokorpi, 2006).

The social/situational context is the actual context in which the learner is currently existing as they access or receive learning from a mobile device (Al-Hmouz et al., 2010). It can be defined by the social interactions, cultural surroundings and rules around communication (Koole, 2009). This context will involve any distractions or interruptions to the learning environment context. Chittaro (2011) points out that using mobile technology can often be a secondary task within our 
social context, mobile phones have introduced an unpredictability, when one person calls another they are not sure what situation that person is in and cannot know whether they are interrupting that person. It is also a common expectation that someone can answer a call at any time as they will always have access to their phone. The mobile device is then an extension of that person's situation, so while a user is interacting with the mobile technology they are also involved with "the world as negotiated and enacted in the moment" (Fischer, 2011, p. 19)

Fischer (2011) further delves into the idea of 'anywhere, anytime' and questions whether people do actually have their devices on them all the time. While Patel et al. (2006 as cited by Fischer, 2011) found that users "keep their phones switched on $85 \%$ of the time on average, but only $58 \%$ of the time on average did they also have the phone within arm's reach." So while mobile devices are definitely a part of a person's daily living, it's not necessarily something that is continuously consumed as some might be led to believe. This is an important consideration as it questions how often and how regularly users would engage with their phones for mobile learning. Fischer (2011) also noted that "when users were away from home, they carried their mobile phone with them significantly more often than when at home." This means that the situational context of a user will often be in a non-constant situation; this being on the move often means "that people can devote only a very limited attention to the device while they are on the move" (Chittaro, 2011, p.331). This brings up an interesting conflict that needs to be taken into account when designing, even though learners are able to learn on the move there is also higher chance of distraction and interruptions.

\section{Learning Environment Context}

Mobile learning has the ability to cross the boundary of a learners context and "facilitate sense making activities" (Rogers et al., 2009). The learner is now able to move beyond the classroom, both taking the classroom with them while being removed from that context. The mobile learning environment is able to create its own environment within any situational context and engage the learner (Alvarez et al., 2011; Patokorpi, 2006).

The mobile learning environment is thus created in the way that it is delivered and the learning styles that it caters for (Al-Hmouz et al., 2010). The mobile learning context is where the situational and learner's personal context meet with the digital sphere. The digital sphere can be seen as the device aspect looking at the functional ability of the device, its physical and technical attributes from the hardware and software (Koole, 2009).

This learning space where designers and teachers have the most influence over. Mobile phones have been observed as only being "used for short bursts of times" (Rogers et al., 2009), so learning material would need to cater for such. Being out in the world means that learners can stop and "reflect... deepen their understanding and help integrate their ideas" (Rogers et al., 2009). Furthermore, mobile phones are capable of delivering games that stimulate learning and engagement in a subject (Burdick \& Willis, 2011).

Using mobile devices in museums, it has been observed that children tend to read the device on their own as opposed to when there was no device, where they would work things out together. There is a difference in the learning experience created through mobile devices and this is the learning environment context created (Rogers et al., 2009).

Mobile learning thus includes the learner's personal context within a situational context, and these can be considered physical spheres and by introducing the digital sphere into the learning context we have a mobile learning environment. 


\section{As-Lived Experience}

A theoretical approach to designing for mobile learning should observe the as-lived experience. To create this as-lived lens this paper focuses on the phenomenon as proposed by Winograd \& Flores (1986) from the chapter "using computers: a direction for design" that is built upon an understanding of communication as being made up of commitments and breakdowns. McCarthy \& Wright's (2005) use of felt-life, which is another term for as-lived, within human computer interaction is also focused on in this section. This section falls within the understanding of context for mobile learning design as it provides the lens to understand the learner's context further, though it is particularly influencing on the actual design of the course from a designer's perspective.

As-lived experience is understood as looking at the way that people experience technology in a natural setting, the experience as it is beyond logical thinking and rationalism and within a domain of understanding. It allows us to take into account the complexities of as-lived experiences including emotions, feelings and cognitive beliefs and ask questions that were not previously considered. It also considers people as having a relationship with technology, and that relationship is governed by our values and goals (McCarthy \& Wright, 2005; Winograd \& Flores, 1986). Taking an as-lived approach means looking at the world as it is "sensed and experienced" (McCarthy \& Wright, 2005, p. 262) by people. Within a mobile learning designing perspective this means understanding how users interact and feel about learning using mobile technology in their specific context (Winograd \& Flores, 1986). The as-lived experience provides an approach to considering the usability of the technology within the context of learning.

Winograd \& Flores (1986) look at designing systems in an ontological framework "that facilitate human work and interaction." Mobile learning is an interactive space as discussed previously when looking at the different contexts. This ontological design "constitutes an intervention in the background of our heritage, growing out of our already existent ways of being-in-the-world, and deeply affecting the kinds of beings that we are." The as-lived approach to thinking allows us to think about the users experience in designing a mobile learning environment. Winograd \& Flores (1986) propose phenomenological insights into the ways of design.

The three major ones are readiness-to-hand, anticipation of breakdown and the blindness created by design; these phenomenologies can be combined into our model for consideration, bringing concepts of context, thoroughness and domains of understanding.

"Readiness to Hand" is when something is designed in such a way that a user can simply use it without much thought such as driving a car or making a phone call; it is a concept that is important to consider in design in ensuring that the user is comfortable with and doesn't need handholding. Part of this is to make sure that a domain of understanding is defined, this is the context that is created within the mobile learning system; once this is defined then it is easy to identify where parts of the system might confuse or deter a learner, "a bad design forces the user to deal with complexities that belong to the wrong domain" (Winograd \& Flores, 1986).

This can also be seen as an "anticipation in breakdown", identifying something that might cause a break in communication between the device and the use; designers should be aware of anything like this; a breakdown is not a negative situation to be avoided, but a situation of nonobviousness, in which the recognition that something is missing leads to 'unconcealing' (Winograd \& Flores, 1986). The breakdowns create clear objectives, providing possibilities for action for when these breakdowns happen (Winograd \& Flores, 1986).

Another concept of Winograd \& Flores (1986) is blindness in design; this asks us, when creating the mobile learning system what is not being considered; for instance, in the creation of a searchable online database of books the user is able to find books more efficiently but the ability to 
browse for similar material. For design, this means taking into account many possibilities to know what to expect.

McCarthy \& Wright (2005, p.262) use the term "felt-life" and explain how combining this lens with human computer interaction will allow us to deal with "issues such as resistance, identity, and attachment that are not otherwise addressed in HCI", As the as-lived experience takes into account the sensual and emotional experiences that cannot necessarily be measured and gives us a clearer understanding. Technology is increasingly becoming a part of our daily life, especially mobile technology, and they are more than just work tools but are part of our social lives as well. This relationship with technology can define the way we use and interact with technology, making this as-lived lens necessary.

Nussbaum (2001) connects people's actions to their emotion by explaining that emotions are linked to a person's "goals, needs, desires, and values" which can be used to locate the relationship between self and technology. By recognizing emotions, the as-lived approach considers these emotions as responding to the immediate environment in the interests of that person's goals.

"Although these feelings are associated with bodily sensations, they never quite belong in the body, rather they are qualities of interactions between organisms and things in their environments" (McCarthy \& Wright, 2005, p.264), which gives us some measure of the user's experience that could identify underlying reasons for breakdowns.

"For people, feeling is inevitably intertwined with language, intentions, and values. Combined with language and intention, feelings become more sophisticated forms of knowledge or sense making, partly because of their proliferation and partly because of their association with a person's sense of self" (McCarthy \& Wright, 2005, p.264). This understanding means that there are underlying reasons to people's resistance to technology, that can be understood through the aslived approach, and might otherwise be swept over and not considered; it "requires us to model people as always involved and always having preferences, priorities, and values" (McCarthy \& Wright, 2005, p.270). There is the need to explore "how the person felt about the experience, what it meant to them, whether it was important to them, and whether it sat comfortably with their other values and goals" (McCarthy \& Wright, 2005, p.266) to get an understanding of that relationship between technology and the user.

\section{Existing Processes for Mobile Learning Design}

Current research around mobile learning design is very focused on only a few aspects of the mobile learning paradigm. The research described below is considered in the method that this paper proposes and are combined in a way that seemed logical and relevant.

Mobile Human Computer Interaction is an area of research that is "concerned with the reasons and ways in which people act and interact with data that is accessed through the mobile device" (Botha et al., 2010, p.33) looking at the relationship that people have between their mobile devices. Botha et al. (2010) has summarized mobile human computer interaction into comprising of "five interlinked focus areas: mobile users, mobile devices, mobile networks, mobile business processes and mobile use".

Hemabala \& Suresh (2012) identify three modules to mobile learning: (1) the content module; consisting of "five authoring tools: development, management, distribution, collaboration, delivery". The delivery and distribution described here are inherently similar, and collaboration can be rather seen as a characteristic of the mobile learning system, while the management tool is part of the users experience is similar to the development tool. (2) The learning module is described as where learning takes place and how it should be designed through a behaviorist or constructivist approach. The active approach to learning is advocated for. (3) The evaluation module is about knowledge sharing and management which goes back to the collaboration and management au- 
thoring tools that are mentioned in the content module. The evaluation itself is about performance and measuring knowledge acquisition.

The aspects that are most prominent from this model are the content development, related to pedagogy and specifically referring to "Dale's cone of experience" where active learning is shown to be more effective than passive learning (Hemabala \& Suresh, 2012).

Killilea (2012) has proposed five best practices to the design and use of mobile learning. When designing a mobile course (1) clear objectives to the course should be setup and made clear to all learners. This includes "goals, expectations, and standards to be met." (2) Feedback should be built into the course consistently; using assessments is one way of allowing learners to gain feedback and see how they are faring in meeting the objectives of the course. (3) Content should be structured to some extent, while learners are able to choose where and when they'll learn, the content should be easily navigable and consistent. (4) Active learning techniques should be used in the course where possible and should encourage to "be thinking about how the material relates to them on a personal level". Last but not least, (5) realistic timeframes for lessons should be considered so that learners plan their course schedule at the start, ensuring that learners also have the flexibility of learning at their own pace.

Ryokai (2012) proposes four design principles for mobile learning: Connect, contextualize access, capture and multimodal. These design principles refer to the importance of creating a connection between what takes place in the classroom and what is delivered through the mobile device; and the importance of creating a personal connection to the material for the learner by ensuring it is relevant and meaningful to the learner. Multimodal refers to making the content accessible via multiple "learning styles: visual, auditory and kinesthetic" (Killilea, 2012).

\section{Objectives to Learning}

Bloom's (1956) taxonomy has been widely referenced and used over the last few decades. The main principle behind the taxonomy is the way teaching is practiced by creating objectives that encompass higher levels of thinking. The taxonomy has been made easily accessible through various depictions such as pyramids and wheel diagrams to explain the concepts (Krathwohl, 2002; Munzenmaier \& Rubin, 2013). Figure 3 illustrates the progressive levels of Bloom's taxonomy.

Bloom's taxonomy is highly suitable for putting together objectives around learning that apply to all levels of thinking and crosses the knowledge dimensions. Creating objectives are made simply by choosing a level of thinking, choosing a verb of learning that is associated to that level and then choosing an activity for that level. For example, an objective around understanding would be to get learners to 'interpret' through the use of a 'report'. They can further add value to this objective by adding 'real-world' conditions and criteria to the activity and knowledge area (Munzenmaier \& Rubin, 2013).

By selecting objectives along this taxonomy, one also chooses the activities and hence the content that will be required for the course. So it can be seen how the pedagogy and objectives influence the content that is to be delivered for learning. 


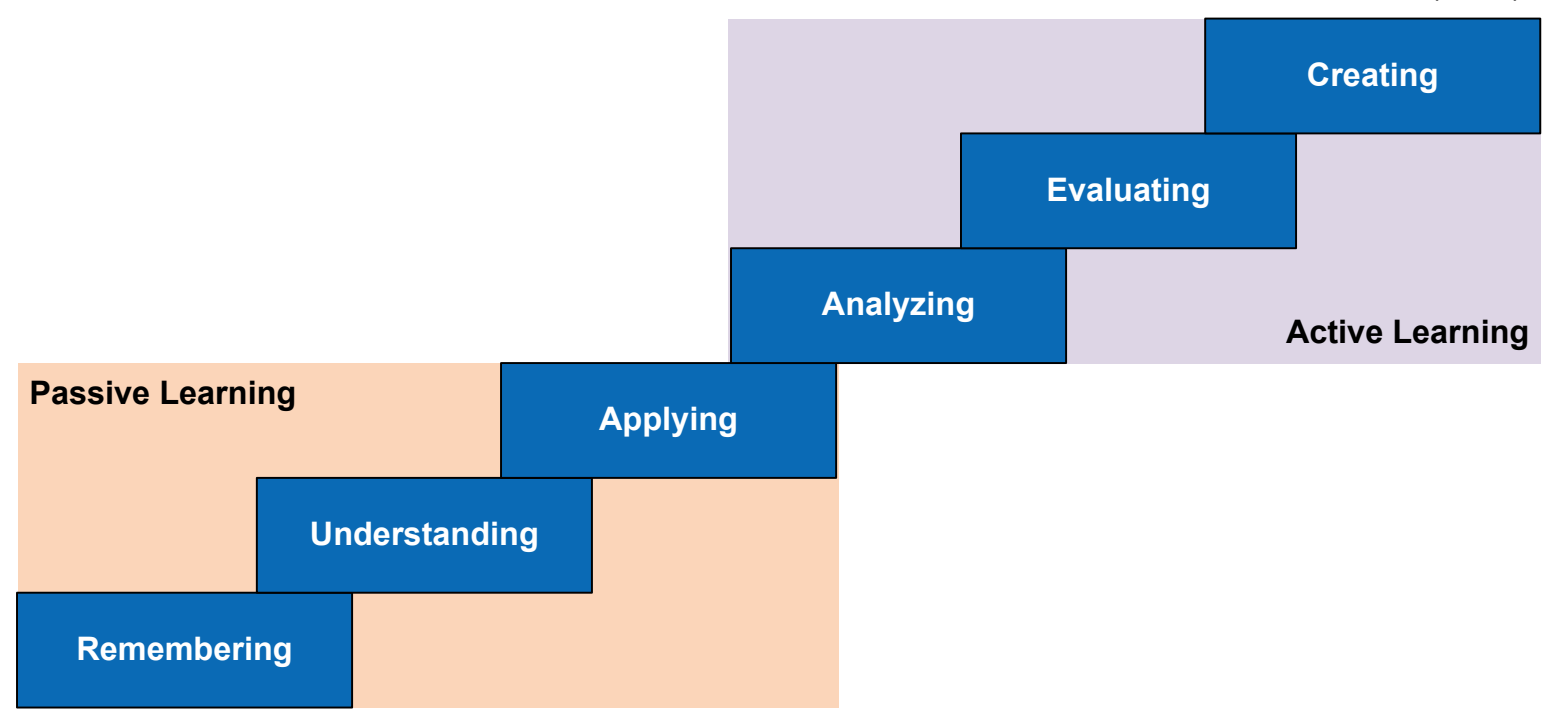

Figure 3: Combining pedagogy for mobile learning design (Krathwohl, 2002)

\section{Knowledge Dimensions}

There are various aspects of learning styles, from how a learner absorbs and translates information to the different ways in which this can be achieved. Franklin (2011) suggests that educators must "enable learners to reach their potential" by allowing learners to access knowledge beyond the classroom; encouraging critical thinking and problem solving skills and encouraging learners to take responsibility for their learning. Learning style is important to the design of mobile learning. It is then necessary to draw from common pedagogical understandings and apply this to mobile learning where applicable. The pedagogy and understandings that underlie a mobile learning course will ultimately guide the way in which the course is put together. Clarity on what learning styles to focus on from the start will give a method for designing mobile learning more direction and purpose. Furthermore, it is necessary to link where mobile learning supports these learning styles and to take advantage of these opportunities.

\section{Access to Knowledge}

Mobile technology allows instructors to share information in numerous ways, that caters for various learner styles such as "auditory (audio lectures), visual (diagrams, graphs), and linguistic (Word, PowerPoint), (Al-Hmouz et al., 2010, p. 785). Being able to share and distribute information to learners is important for extending learning to outside of the formal classroom and "allowing flexible and instance access to rich digital resources" (Cheon et al., 2012) in an informal environment through mobile technology.

It has been identified in some studies that learners use the internet mostly for help on their homework and for social networking (Bennett, Maton, \& Kervin, 2008). "Learning as it takes place informally and via social media tools is deeply social as is design" (Burdick \& Willis, 2011, p.548) and is an important part of increasing access to knowledge to learners.

Also, the use of games and simulations as a learning tool, applying the "natural and universal behavior of children and adults" (Costabile et al., 2008) provides the necessary shift towards a constructivist approach that encourages collaboration, problem solving, imagination, communication skills and authentic learning (Bennett et al., 2008; Costabile et al., 2008). 


\section{Responsibility for Learning}

Encouraging learners to take responsibility for their learning also involves giving them an understanding of why they are learning and how learning takes place (Franklin, 2011). There are two popular models that could help in this.

The conscious competence ladder or matrix is a commonly used analogy of how a learner goes through stages of learning. A leaner starts "unconsciously incompetent" where they are not aware of what they don't know and as they learn about something they move up to "consciously incompetent", that gives intrigue to a learner and as they learn and begin to understand they become "consciously competent"; the final stage of the ladder is "unconscious competence" when the learner is now an expert in the topic and does the job without having to think it through (Watkins, Carnell, Lodge, Wagner, \& Whalley, 2002).

Cockburn's (2003) stages of learning are very similar to the competence ladder, he describes the stages as "following", when one is new to a subject people tend to copy and will concentrate on a single method until they get to grips with it; "detaching", is a phase where the learner starts questioning the model and its rules and starts to learn some alternative methods. "Fluency" is a stage where the learner is no longer concerned about which technique to follow and the knowledge is used unconsciously to get the desired outcome

Learners should be taught about learning stages while learning other subjects. To assist learners through the stages of learning, such as the competence ladder, and giving them understanding about how that works can help the process. This can also be seen as an abductive approach that allows for deeper insight and reflection (Watkins et al., 2002).

\section{Thinking behind the Learning}

It is important that we do not box learners into a type, as individuals can have parts of each learning style. This makes it difficult for teachers to isolate the right approach to teaching (Watkins et al., 2002). The traditional passive learning assumes that learners are best taught by giving them knowledge and allowing them to assimilate this on their own as opposed to active learning approaches that rely on a more social process; this has become a more favorable approach recently (Schultz, 2011). As can be seen in Figure 3, Bloom's taxonomy could be seen as moving learning from a passive approach to a more active approach in learning. Active learning is very possible through mobile technology through the many functionalities that allow for "talking and listening, reading, writing, and reflection" (Franklin, 2011).

Abductive reasoning is being discussed as a more viable and logical learning approach that can be translated to mobile technology. "When we encounter a world that rarely supplies all the information we need" (Burdick \& Willis, 2011) then we use abductive reasoning to make the world more understandable. Patokorpi (2006) suggests that the design of learning using technology could be better understood by studying abductive reasoning. Mobile technology is capable of providing "partially formed ideas and understanding" (Rogers et al., 2009) that will engage the natural abductive thinking of learners.

It is possible to take learning approaches and transform them to a different platform as the "learning environment does not change the essential aspects of how people learn" (Franklin, 2011) but can rather support and enhance the learning.

Bloom's taxonomy describes four knowledge dimensions: factual knowledge (where basic information is gained), conceptual knowledge (where tools and techniques and diagrams are used to understand the functioning of a concept), procedural knowledge (knowing how to do something) and metacognitive knowledge (knowledge of thinking) (Merhbi, 2011). 
Metacognitive knowledge can be tied back to the responsibility of learning objectives; procedural and conceptual knowledge are linked to critical thinking and factual knowledge is linked to the objective of having access to knowledge as shown in Figure 4. It is useful for the designer of the course to see where the different knowledge dimensions are addressed by the objectives.

Franklin (2011)

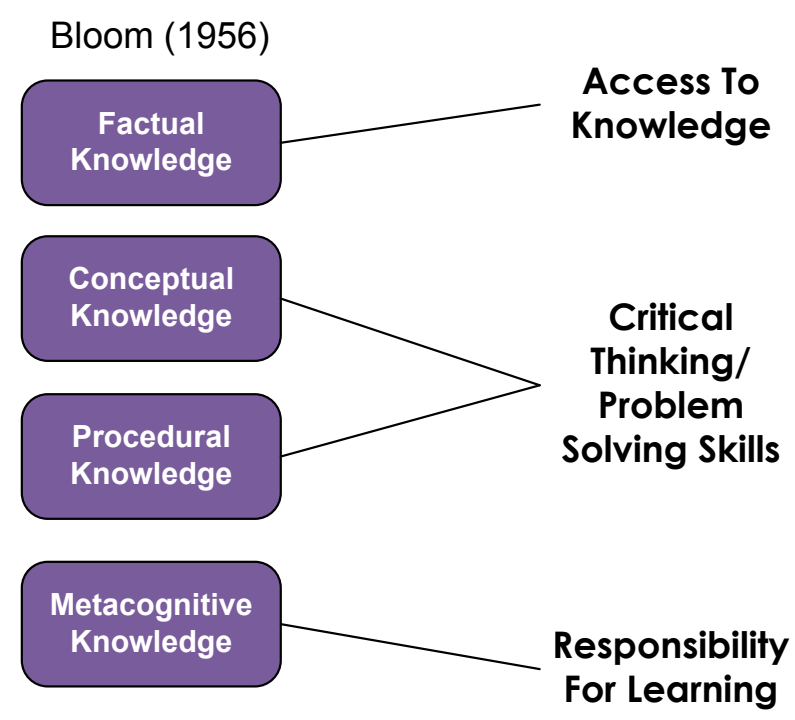

Figure 4: Knowledge dimensions linked to main objectives of learning (Merhbi, 2011; Franklin, 2011)

\section{Categories of Learning Theory}

From Cheon et al. (2012) and Naismith et al. (2004) seven broad categories of learning activity theories can be put forth that mobile learning can support or be used because of the characteristics that lend to these learning activities. The first, is that of an individualized learning; mobile learning allows for learners to "pace learning at their own speed" (Cheon 2012) so that they are not left behind when stuck on a concept or losing interest if it is too slow. The second activity is behaviorist learning, where the learner is able to get learning material through their mobile device, respond to it and get the appropriate feedback to encourage learning (Naismith et al., 2004).

The third category is a constructivist learning, this is where abductive thinking comes in, and the learner will "construct new ideas or concepts based on both their previous and current knowledge"(Naismith et al., 2004). In this case the learner is encouraged to understand principles actively on their own. mobile learning is capable of providing the collaborative environment necessary for this alongside the supportive tools and real context to do so (Naismith et al., 2004). The fourth category is situated learning, this allows students to learn within a real context, where the information provided is based specifically on the learners surroundings or situation, and they can be guided through an unfamiliar task or activity to achieve real world learning (Cheon et al., 2012; Naismith et al., 2004). Situated Learning gives rise to specific outcome based opportunities: " problem- based learning, case-based learning, and context-aware learning" (Naismith et al., 2004).

Fifth, is collaborative mobile learning, that uses the ability to interact and communicate both with mentors and other learners to complete tasks and activities towards learning objectives (Cheon et al., 2012; Naismith et al., 2004). The sixth category is informal learning. mobile learning allows 
for students to learn beyond the classroom at their own pace and preference, as well as learning that might not have occurred in a more structured environment (Cheon et al., 2012; Naismith et al., 2004; Siemens, 2004). Siemens (2004) considers informal learning to be one of the most significant categories in the learning experience. The last category suggested by Naismith et al. (2004) is "learning and teaching support, this is the ability for mobile learning to help with administration and coordination of resources and learners in delivering a successful curriculum (Naismith et al., 2004).

Mobile learning allows for teachers to deliver the appropriate content within the many learning styles available, while encouraging learner responsibility and encouraging particular skills in problem solving and critical thinking. With the knowledge that mobile learning can offer all this, the next question that arises is how we get it to do this, and ensure that quality learning is happening. The next section delves in to the "as-lived experience" as a lens to a design method.

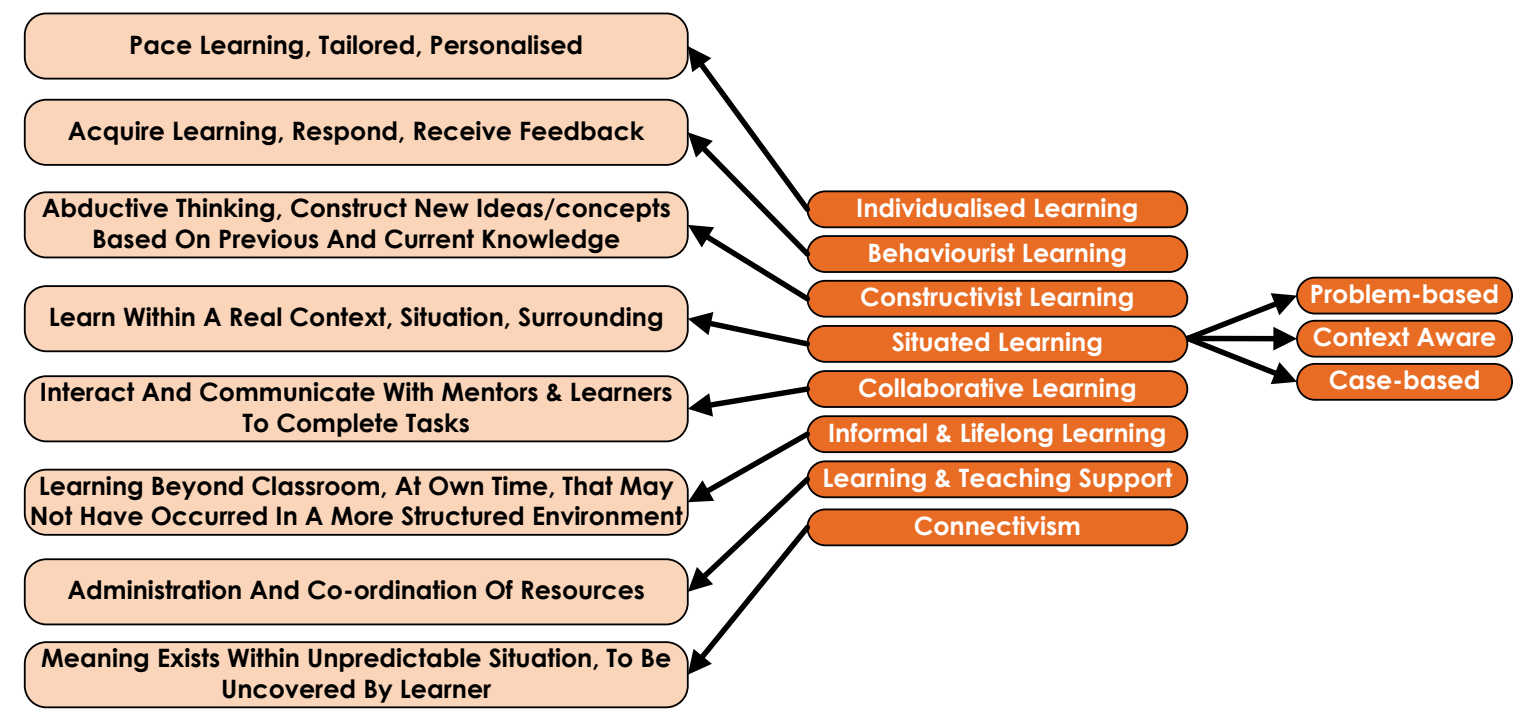

Figure 5: Combination of m-learning categories from theory

(Cheon et al., 2012; Naismith et al., 2004; Siemens, 2004)

An addition to this list of categories is one proposed by Siemens (2004), who elaborates on the theory of connectivism, which is contrasted from that of behaviourism and constructivist approaches. It is based on the idea of chaos, "the breakdown of predictability" (Siemens, 2004) and upon the idea that meaning exists and it only needs to be uncovered by the learner. So learning takes place in an environment that is constantly changing and mostly out of the learner's control, and that the learning "is focused on connecting specialized information sets, and the connections that enable us to learn more" (Siemens, 2004). These categories are summarised in Figure 5 for easy reference.

\section{A Method for Mobile Learning}

For the method being proposed in this paper, Figure 6 outlines the eight steps to be followed in designing and implementing mobile learning in a logical flow. The green blocks, pedagogy and context, are influencing concepts for the mobile course. The orange blocks illustrate the general process of considering the objectives, the content, the delivery and the structure of the course and the last two blue blocks, implementation and evaluation, are outside of the design of the course and are included as completing the process ensuring that the design met its objectives. Figure 6 
gives a brief indication of the points of discussion within each aspect of the method described in Figure 7.

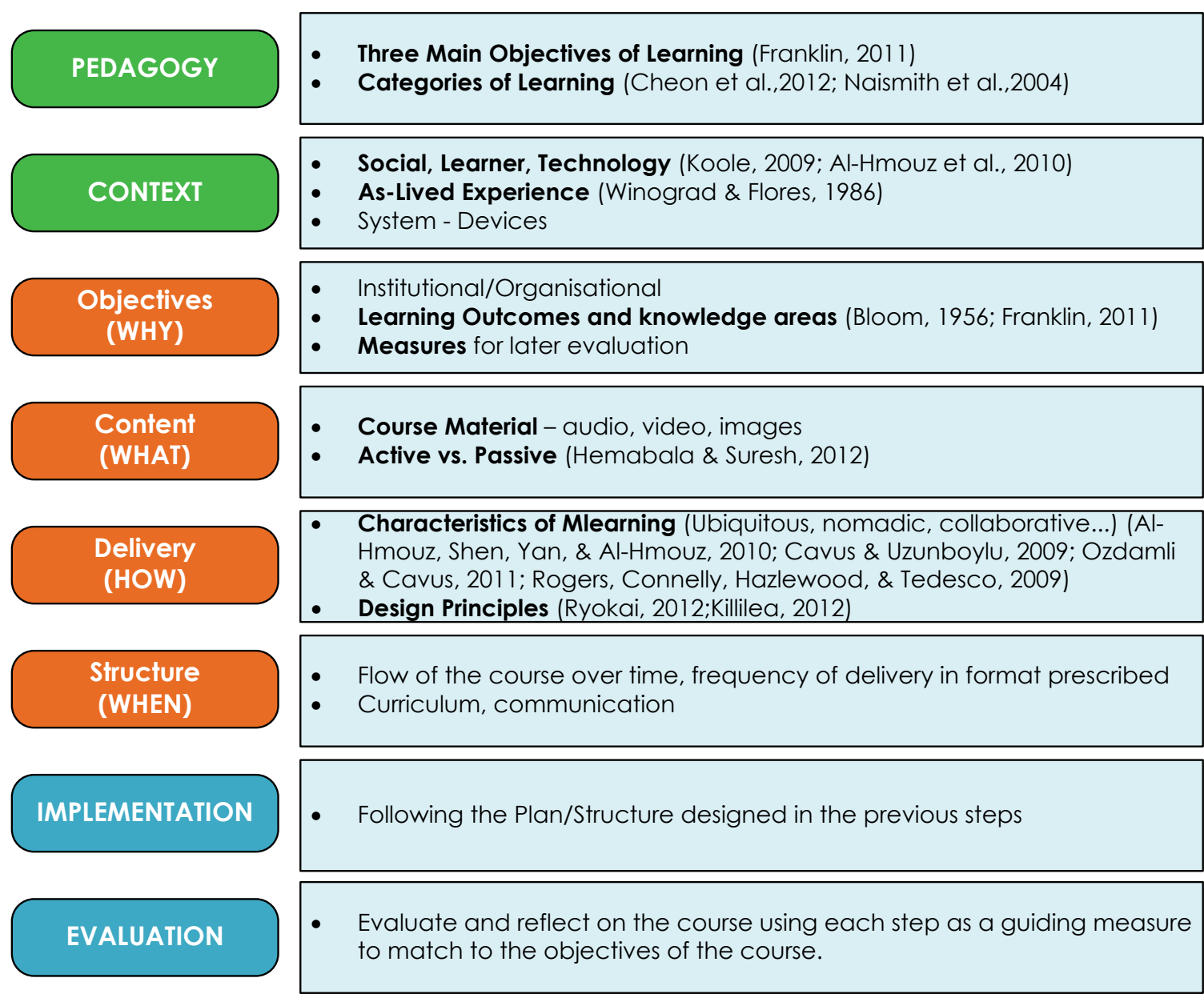

Figure 6: Discussion points around a mobile learning design method

Identifying objectives is the first step in the design, it is the question 'why' are we doing this course and 'what' do we want out of it. The objectives should be made with the pedagogical and contextual considerations in mind. Initial objectives may be at an institutional or organizational level and then working down to the learner, it is important to define these and ensure that they are measurable so as to be able to evaluate the success of the course later on. As it can be seen in Figure 7, objectives will be the crux of the design as it influences all other aspects of design. If a new objective comes to light then all other aspects of design need to be reconsidered.

Pedagogy speaks to the learning styles, as shown in Figure 6, it is interlinked with the objectives of the course and the 'how' will it be delivered aspect. The designer must decide how to cater for the various learning styles through audio, visual and interactive means. Using the main objectives of learning as outlined by Franklin (2011) to guide the objectives of the course the designer should be asking how the course is (1) enabling learners to reach their potential by allowing learners to access knowledge beyond the classroom; (2) encouraging critical thinking and problem solving skills and (3) encouraging learners to take responsibility for their learning. It is also useful to identify in the objectives of the course what category of learning this course will be and what that means for how it needs to be designed. Taking Bloom's taxonomy into account the de- 
signer may want to use the overarching objective of moving a learner to a higher level of thinking. The eight categories as described earlier in the paper by Naismith et al. (2004) and Cheon et al. (2012) provide a good base for ways to reach these objectives.

Context is a large area that needs to be considered and depending on the category of learning chosen the context may or may not be more crucial to the success of the course; it ties strongly to the objectives of the course and the 'how' will it be delivered aspect. From Al-Hmouz et al. (2010) and Koole (2009) this paper grouped the contexts into three major categories: (1) learner personal status that takes into account personal motivation andprior knowledge of the learner (2) situational context that looks at where the learner is using the course, how often and when and what kind of social environments; (3) learning environment context is the the link between what the device can offer, the content and engagement with the learner. For each of these the designer should be able to identify the 'target audience' and how these contexts influence the design of the course so as to bring the awareness into forming the objectives and in how the course will be delivered. Nomadicy features in this area, as decisions around whether to deliver the content through native applications or to keep it web based will be influenced by the learner's connectivity and access to internet. The context also brings in the awareness of the as-lived experience where questions around readiness-to-hand, anticipation of breakdown and the blindness created by design can be offered to assist in usability and consideration of the user in design.

Content is the 'what' is being taught. It's any research, collecting of necessary information, and resources. It's not necessarily creating the materials to be delivered but rather ensuring that the objectives are met and all necessary information is available and can be made ready for the mobile learning platform. The information made available here will feed directly into the delivery and structure of the course.

Delivery asks the question of 'how' we are going to get the information to the learners. The objectives, pedagogy and context that have already been considered should almost trigger the how it needs to happen. In this stage we are bringing in common design principles that were discussed earlier on and the various characteristics of mobile learning as described in Figure 1. This is the point at which the decision on how to manipulate the material can be taken, for example what aspects will be made available through audio or images. The technology aspect here also speaks to the usability and design of the platform, where functionality may need to be prescribed or restricted depending on the situation.

Structure is the 'when' will we deliver the content to meet our objectives within the appropriate context and pedagogical considerations. This should be the final stage of the planning. It's looking at the timing of the course, bringing in all the previous aspects and seeing how needs to flow, ensuring it is put together in a way that will guide learners without being restrictive and allowing for the flexibility that the mobile learning environment affords. 


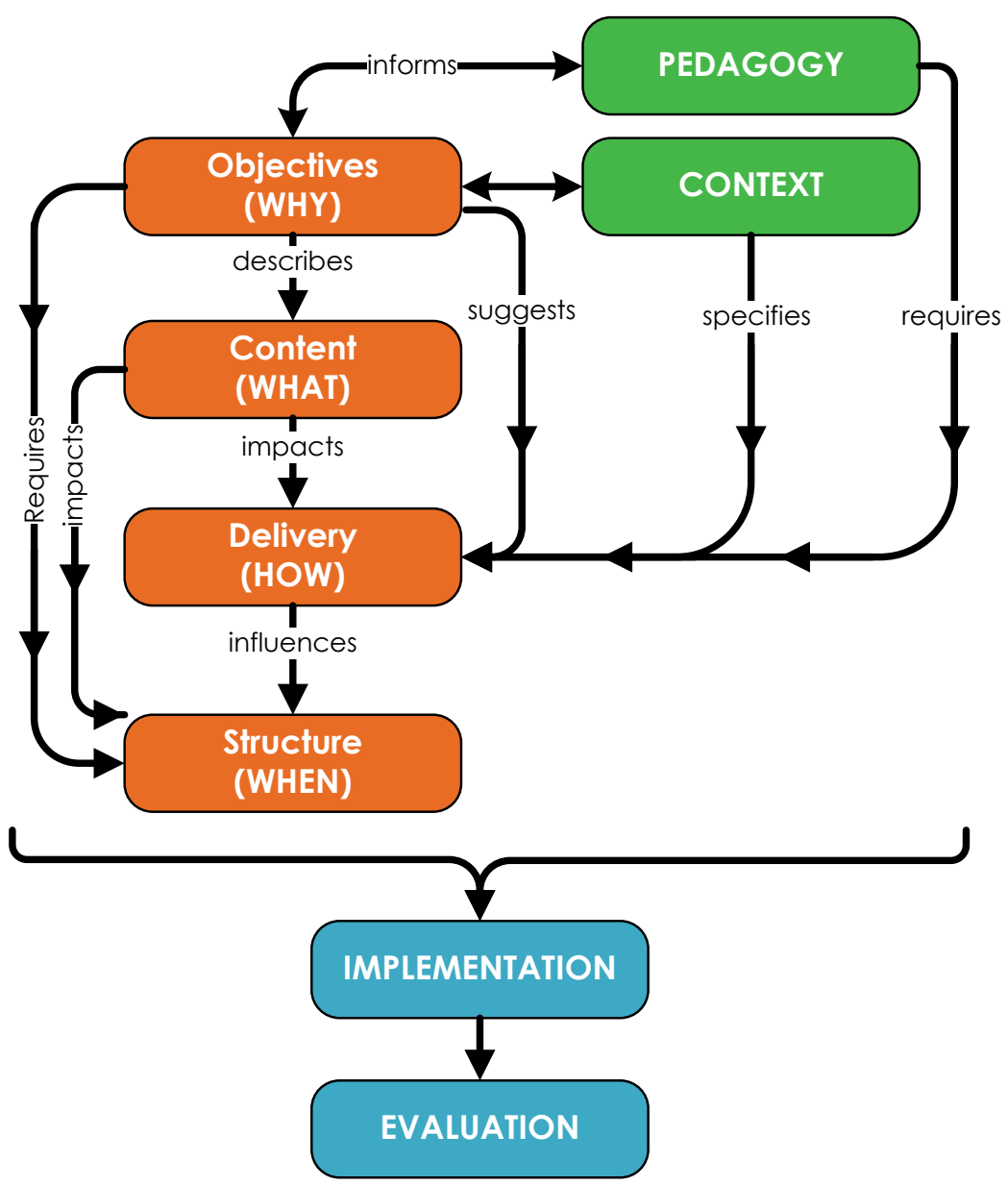

Figure 7: A high-level method for designing mobile learning

While implementation and evaluation of the mobile learning course are separate from the designing of the mobile learning course, it is important to note that in implementation the plan that has been drawn out from the method is being followed and should be detailed enough to do so. The evaluation phase will also be influenced by the various aspects in the method, as the method allows for generalized areas to evaluate the mobile learning course by. The evaluation should also speak directly to the objectives that should have measurable outcomes.

The value in this method is that it brings together the various research topics in a more structured way that allows designers to consider the various aspects of a mobile learning course. By going through these steps the designer is able to get a more holistic view, and is less likely to only focus on one aspect such as personalisation while ignoring other influencing theories. The method is generalized, in the hopes that can cater for future research to be brought into it.

\section{Conclusion}

Mobile learning can be seen as a combination of mobile technology and its affordances that create a unique learning environment and opportunities for learning that can span across time and place. Mobile technology is growing at a rapid rate around the world, and becoming ever more accessible. Technology is emerging and closing the gap towards being a viable tool for mobile learning. It's a social platform that creates environments for communication, understanding, and transfer of information. Its ability to cater for varying learning styles through various features, its link to communication and its social context make it a very attractive tool for learning. The main 
characteristics that have been identified with mobile technology are nomadicy, ubiquity, context sensitivity, personalisation, and interaction.

It is important that mobile learning exists within pedagogy and that designers have an understanding of the contexts that learners exist in. mobile learning can cater for various learning styles through varying delivery methods. Learning is knowledge that is transferred through communication and mobile learning has the ability to support varying learning styles.

By combining the various aspects of mobile learning and the research in these areas, this paper has proposed a method for mobile learning that does not prescribe the content and structure but rather facilitates the process of planning and creating a course while ensuring that the various aspects such as technology, context, usability, and pedagogy are considered along with the objectives of the course. It is hoped that this research can create a central point of reference to more detailed and focused research around mobile learning, allowing for improved mobile learning courses.

\section{References}

Abdous, M., \& Yen, C.-J. (2010). A predictive study of learner satisfaction and outcomes in face-to-face, satellite broadcast, and live video-streaming learning environments. The Internet and Higher Education, 13(4), 248-257. doi:10.1016/j.iheduc.2010.04.005

Al-Hmouz, A., Shen, J., Yan, J., \& Al-Hmouz, R. (2010). Enhanced learner model for adaptive mobile learning. Proceedings of the 12th International Conference on Information Integration and Web-based Applications \& Services - iiWAS '10, 783 - 786. doi:10.1145/1967486.1967614

Al-masri, E., \& Mahmoud, Q. H. (2012). MLDF : Discovering mobile learning content using mobile devices, 603-608.

Ali, A., Ouda, A., \& Capretz, L. F. (2012). A conceptual framework for measuring the quality aspects of mobile learning. Bulletin of the IEEE Technical Committee on Learning Technology, 14(4), 31-34.

Alvarez, C., Alarcon, R., \& Nussbaum, M. (2011). Implementing collaborative learning activities in the classroom supported by one-to-one mobile computing: A design-based process. Journal of Systems and Software, 84(11), 1961-1976. doi:10.1016/j.jss.2011.07.011

Arnold, M. (2003). On the phenomenology of technology: The "Janus-faces" of mobile phones. Information and Organization, 13(4), 231-256. doi:10.1016/S1471-7727(03)00013-7

Bennett, S., Maton, K., \& Kervin, L. (2008). The "digital natives" debate: A critical review of the evidence. British Journal of Educational Technology, 39(5), 775-786. doi:10.1111/j.1467-8535.2007.00793.x

Bloom, R. S. (1956). Taxonomy of educational objectives, Handbook I: The cognitive domain. New York, New York, USA: David McKay Company.

Botha, A., Herselman, M., \& Van Greunen, D. (2010). Mobile user experience in an mlearning environment. Proceedings of the 2010 Annual Research Conference of the South African Institute of Computer Scientists and Information Technologists on - SAICSIT '10, 29-38. doi:10.1145/1899503.1899507

Bray, D., Epstein, M., Hill, T. R., \& Thomas, D. (2006). AMCIS 2006 panel report : The web as a digital reflection of reality. Communications of the Association for Information Systems, 18(November), 130.

Burdick, A., \& Willis, H. (2011). Digital learning, digital scholarship and design thinking. Design Studies, 32(6), 546-556. doi:10.1016/j.destud.2011.07.005

Cavus, N., \& Al-Momani, M. M. (2011). Mobile system for flexible education. Procedia Computer Science, 3, 1475-1479. doi:10.1016/j.procs.2011.01.034 
Cavus, N., \& Uzunboylu, H. (2009). Improving critical thinking skills in mobile learning. Procedia - Social and Behavioral Sciences, 1(1), 434-438. doi:10.1016/j.sbspro.2009.01.078

Chen, G. D., Chang, C. K., \& Wang, C. Y. (2008). Ubiquitous learning website: Scaffold learners by mobile devices with information-aware techniques. Computers \& Education, 50(1), 77-90. doi:10.1016/j.compedu.2006.03.004

Cheon, J., Lee, S., Crooks, S. M., \& Song, J. (2012). An investigation of mobile learning readiness in higher education based on the theory of planned behavior. Computers \& Education. doi:10.1016/j.compedu.2012.04.015

Chittaro, L. (2011). Designing visual user interfaces for mobile applications. Proceedings of the $3 r d$ ACM SIGCHI symposium on Engineering interactive computing systems - EICS '11, 331. doi:10.1145/1996461.1996550

Cockburn, A. (2000). Agile software development, 27 - 41. Retrieved from http://www.ccs.neu.edu/home/lieber/com1205/w03/lectures/lec1d-short-agile-sd.ps

Costabile, M. F., Angeli, A. De, Lanzilotti, R., Ardito, C., Buono, P., \& Pederson, T. (2008). Explore! Possibilities and challenges of mobile learning. CHI 2008 Proceedings (pp. 145-154).

Fischer, J. (2011). Understanding receptivity to interruptions in mobile human-computer interaction. Retrieved from http://etheses.nottingham.ac.uk/2499

Franklin, T. (2011). Mobile learning : At the tipping point. The Turkish Online Journal of Educational Technology, 10(4), 261-275.

Hemabala, J., \& Suresh, E. (2012). The frame work design of mobile learning management system. International Journal of Computer and Inforamtion Technology, 01(02), 179-184. Retrieved from http://www.ijcit.com/archives/volume1/issue2/Paper010224.pdf

Kearney, M., Schuck, S., Burden, K., \& Aubusson, P. (2012). Viewing mobile learning from a pedagogical perspective. Research in Learning Technology, 20(1063519), 1-17. doi:10.3402/rlt.v20i0/14406

Ketterl, M., Heinrich, T., Mertens, R., \& Morisse, K. (2007). Enhanced content utilisation: Combined reuse of multi-type e-learning content on mobile devices. IEEE Multidisciplinary Engineering Magazine, $2(2), 61-64$.

Killilea, J. (2012). Leveraging mobile devices for asynchronous learning: Best practices. scs.org. University of Central Florida. Retrieved from http://www.scs.org/upload/documents/conferences/autumnsim/2012/presentations/etms/4_Final_Subm ission.pdf

Kjeldskov, J., \& Stage, J. (2012). Combining ethnography and object-orientation for mobile interaction design: Contextual richness and abstract models. International Journal of Human-Computer Studies, 70(3), 197-217. doi:10.1016/j.jhhcs.2011.10.004

Koole, M. (2009). A model for framing mobile learning. In M. Ally (Ed.), Mobile learning: Transforming the delivery of education and training (pp. 25-47). Retrieved from http://books.google.com/books?hl=en\&lr=\&id=Itp60WteuJsC\&oi=fnd\&pg=PA25\&dq=A+Model + for + Framing + Mobile + Learning\&ots=5XHON2HQsc\&sig=hRVpUj9HL8LAKTtNTwxqHki4-WY

Krathwohl, D. R. (2002). A revision of Bloom's taxonomy: An overview. Theory into Practice, 41(4), 212-218.

McCarthy, J., \& Wright, P. (2005). Putting "felt-life" at the centre of human-computer interaction (HCI). Cognition, Technology \& Work, 7(4), 262-271. doi:10.1007/s10111-005-0011-y

Merhbi, A. (2011). Bloom's revised digital taxonomy wheel \& the knowledge dimension. educteachalogy. Retrieved February 22, 2013, from http://eductechalogy.org/index/archives/207

Munzenmaier, C., \& Rubin, N. (2013). Bloom's taxonomy: What's old is new again. Perspectives. The Elearning Guild Research. 
Naismith, L., Lonsdale, P., Vavoula, G., \& Sharples, M. (2004). Literature review in mobile technologies and learning (pp. 1 - 42). Retrieved from http://citeseerx.ist.psu.edu/viewdoc/summary?doi=10.1.1.136.2203

Nussbaum, M. (2001). Upheavals of thought: The intelligence of emotions. Cambridge: Cambridge University Press.

Ozdamli, F., \& Cavus, N. (2011). Basic elements and characteristics of mobile learning. Procedia - Social and Behavioral Sciences, 28, 937-942. doi:10.1016/j.sbspro.2011.11.173

Parsons, D., \& Ryu, H. (2006). A framework for assessing the quality of mobile learning. Proceedings of the 11th International Conference for Process Improvement, Research and Education (INSPIRE), Southampton Solent University, UK, 13.

Patokorpi, E. (2006). Role of abductive reasoning in digital interaction. Åbo: Åbo Akademi University Press. Doctoral Thesis.

Rogers, Y., Connelly, K., Hazlewood, W., \& Tedesco, L. (2009). Enhancing learning: A study of how mobile devices can facilitate sensemaking. Personal and Ubiquitous Computing, 14(2), 111-124. doi:10.1007/s00779-009-0250-7

Ryokai, K. (2012). Mobile learning with the engineering pathway digital library. International Journal of Engineering Education, 28(5), 1119-1126.

Schultz, M. (2011). Interpreting the learning styles of traditional and distance learning students. Journal of College Teaching \& Learning, 1(5), 19-28. Retrieved from http://cluteonline.com/journals/index.php/TLC/article/viewArticle/1941

Sha, L., Looi, C.-K., Chen, W., Seow, P., \& Wong, L.-H. (2012). Recognizing and measuring selfregulated learning in a mobile learning environment. Computers in Human Behavior, 28(2), 718-728. doi:10.1016/j.chb.2011.11.019

Siemens, G. (2004). Connectivism : A learnig theory for the digital age. elearnspace. Retrieved February 18,2013 , from http://www.ingedewaard.net/papers/connectivism/2005_siemens_ALearningTheoryForTheDigitalAge. pdf

Watkins, C., Carnell, E., Lodge, C., Wagner, P., \& Whalley, C. (2002). Effective learning. National School Improvement Network, 17(1).

Weilenmann, A., \& Juhlin, O. (2011). Time to revisit mobility in mobile HCI? Proceedings of the 13th International Conference on Human Computer Interaction with Mobile Devices and Services MobileHCI '11, 717. doi:10.1145/2037373.2037495

Williams, P. W. (2009). Assessing mobile learning effectiveness and acceptance. MIS Quarterly, PhD, 110. Retrieved from http://www.paulwwilliamsphd.com/index_files/Assessing_Mobile_Learning_Effectiveness_and_Acce ptance.pdf

Winograd, T., \& Flores, F. (1986). Understanding computers and cognition: A new foundation for design (pp. 162 -179). Menlo Park, California: Addison-Wesley Publishing Company, Inc.

Yordanova, K. (2007). Mobile learning and integration of advanced technologies in education. Proceedings of the 2007 international conference on Computer systems and technologies - CompSysTech '07, 1. doi:10.1145/1330598.1330695

Yousuf, M. I. (2007). Effectiveness of mobile learning in distance education. Turkish Online Journal of Distance Education, 8(4), 114-124. 


\section{Biographies}

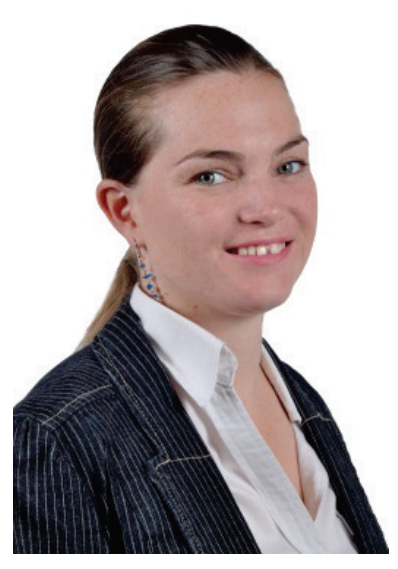

Genevieve Stanton is Innovations Manager at Pétanque Consultancy in South Africa, consulting in business analysis. She has a Post graduate diploma in Business and Systems Analysis in Management of information Systems from UCT and is currently completing her Masters in Information Systems. Her current research is in Mobile Learning.

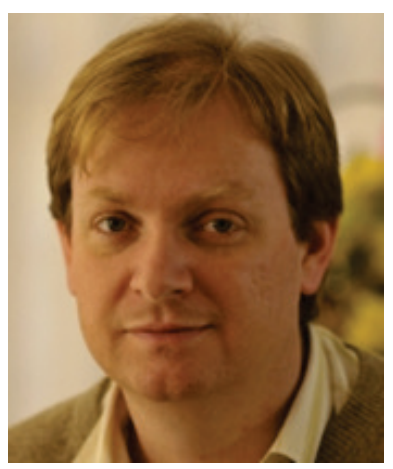

Jacques Ophoff is a lecturer at the Department of Information Systems at the University of Cape Town (UCT), South Africa. He obtained his doctorate in Information Technology from the Nelson Mandela Metropolitan University, South Africa. Before joining UCT he was an IT product manager at an online startup company. His research interests include information security, mobile technologies, and education. 